\title{
STUDY OF GERVICAL BIOPSY OVER A DECADE AT A TERTIARY LEVEL HOSPITAL,
}

\section{NEPAL}

\author{
Tamrakar SR', Shrestha $S^{2}$
}

${ }^{1}$ Department of Obstetrics and Gynecology and ${ }^{2}$ Department of Pathology, Dhulikhel Hospital - Kathmandu University Teaching Hospital, Kavre

\begin{abstract}
Cervical carcinoma is the most common gynecological malignancy and almost curable cancer, if identified at an early stage. Cervical biopsy remains the 'gold standard' for the diagnosis of precancerous cervical lesion. The objective of this study was to review the histopathological findings of cervical biopsy including cervical polypectomy and hysterectomy specimens at Dhulikhel Hospital from January 2008 to December 2018. Out of 2098 cases, almost half of the cases (49.3\%) were of Brahmin/Chhetri castes. There were significant differences in mean ages among hysterectomy cases $(47.55 \pm 9.26)$, cervical biopsy cases $(43.08 \pm 11.50)$ and polypectomy cases $(33.59 \pm 12.47)$ ( $p$ value $<0.005)$. Out of 925 cervical specimens (cervical biopsy and polypectomy), colposcopy and hysteroscopy were performed in $18.2 \%$ and $12.7 \%$, respectively. Out of 1173 hysterectomies, there were 110 cases (9.4\%) of malignancies and cervical cancer was the most common $(67,60.9 \%)$. The mean age of cervical cancer patients was $52.87 \pm 11.94$ years. Cervical cancer detected in age group of $40-59$ years was significantly high ( $p$ value $<0.005$ ). Incidence of cervical cancer was lowest in Brahmin/Chhetris (2.4\%) compared to Newars (3.4\%) and other Janajatis (12.8\%) and the difference was statistically significant ( $p$ value $<0.005$ ). The findings of this study is useful in updating the histopathological pattern of cervical biopsies.
\end{abstract}

\section{KEYWORDS}

Biopsy, cervical cancer, colposcopy, hysterectomy, polypectomy

\section{CORRESPONDING AUTHOR}

Dr. Suman Raj Tamrakar,

Associate Professor, Dhulikhel Hospital-Kathmandu

University Teaching Hospital,

School of Medical Sciences (KUSMS),

Dhulikhel, Kavre, Nepal

Email: drsuman3947@gmail.com 


\section{INTRODUCTION}

Cervical carcinoma is one of the most common gynecological carcinoma and leading cause of mortality in females. ${ }^{1}$ Cervical cancer is almost curable if identified at an early stage. ${ }^{2}$ Five screening methods, namely naked eye visual inspection of the cervix after application of diluted acetic acid (VIA), Lugol's iodine (VILI) or with a magnifying device (VIAM), the pap smear and human papilloma virus (HPV) testing with highrisk probe of the Hybrid Capture-2 assay (HC2) are being used to screen and detect the cervical cancer in precancerous stage. ${ }^{3}$ But these tests may fail to localize the lesion and, cervical biopsy remains the 'gold standard' for the diagnosis of precancerous cervical lesion. ${ }^{4}$

Cervical cancer screening tests along with the confirmatory tests and appropriate treatment for premalignant cervical conditions and cervical cancers were regularly done in Dhulikhel Hospital (DH) since its establishment (1996). Though, there are ample of studies done in the field of cervical cancer globally, only limited publications related to cervical screening tests were available from Nepal, and the available publications were not focused on cervical biopsies. ${ }^{5-8}$ Only two articles related to cervical cancer screening and cervical biopsy were published from DH., ${ }^{9,10}$ Twenty two low grade squamous intraepithelial lesions (LSIL) and four frank malignant cases were detected in 1062 pap smear examination. ${ }^{9}$ In a study of 1922 pap smear, there was $0.4 \%$ high grade squamous intraepithelial lesions (HSIL). In another study done in Dhulikhel hospital, 1.3\% moderate SIL, $6.7 \%$ SIL and 5.3\% frank malignancy were detected in 75 cervical biopsy. ${ }^{10}$
Therefore, this study was carried out to investigate and analyze the histopathological findings in targeted cervical biopsy, polypectomy specimens and hysterectomy specimens evaluated and/or treated in Dhulikhel Hospital, a University Hospital of Kathmandu University.

\section{MATERIALS AND METHODS}

This was a study of the histopathological findings in targeted cervical biopsy, polypectomy specimens and hysterectomy specimens evaluated and/or treated cases in DH from January 2008 to December 2018. This study was carried out in the Department of Obstetrics and Gynecology. The medical records from OPD patients, inpatients and histopathology records including electronic records were reviewed. Socio-demographic information (caste, age) and diagnostic procedures were also analyzed.

Ethical clearance was taken from the hospital research committee (IRC-KUSMS). All data were analyzed by SPSS 16 packages using appropriate statistical tools.

All the cases were initially categorized into cervical tissue and hysterectomy specimen groups for analysis purpose. The cervical tissue group was further divided into targeted cervical biopsy group and cervical polypectomy group as per need. Though histopathological findings and other information were analyzed in all these three groups (targeted cervical biopsy, polypectomy specimens and hysterectomy specimens), meticulous analysis was carried out primarily in targeted cervical biopsy group.

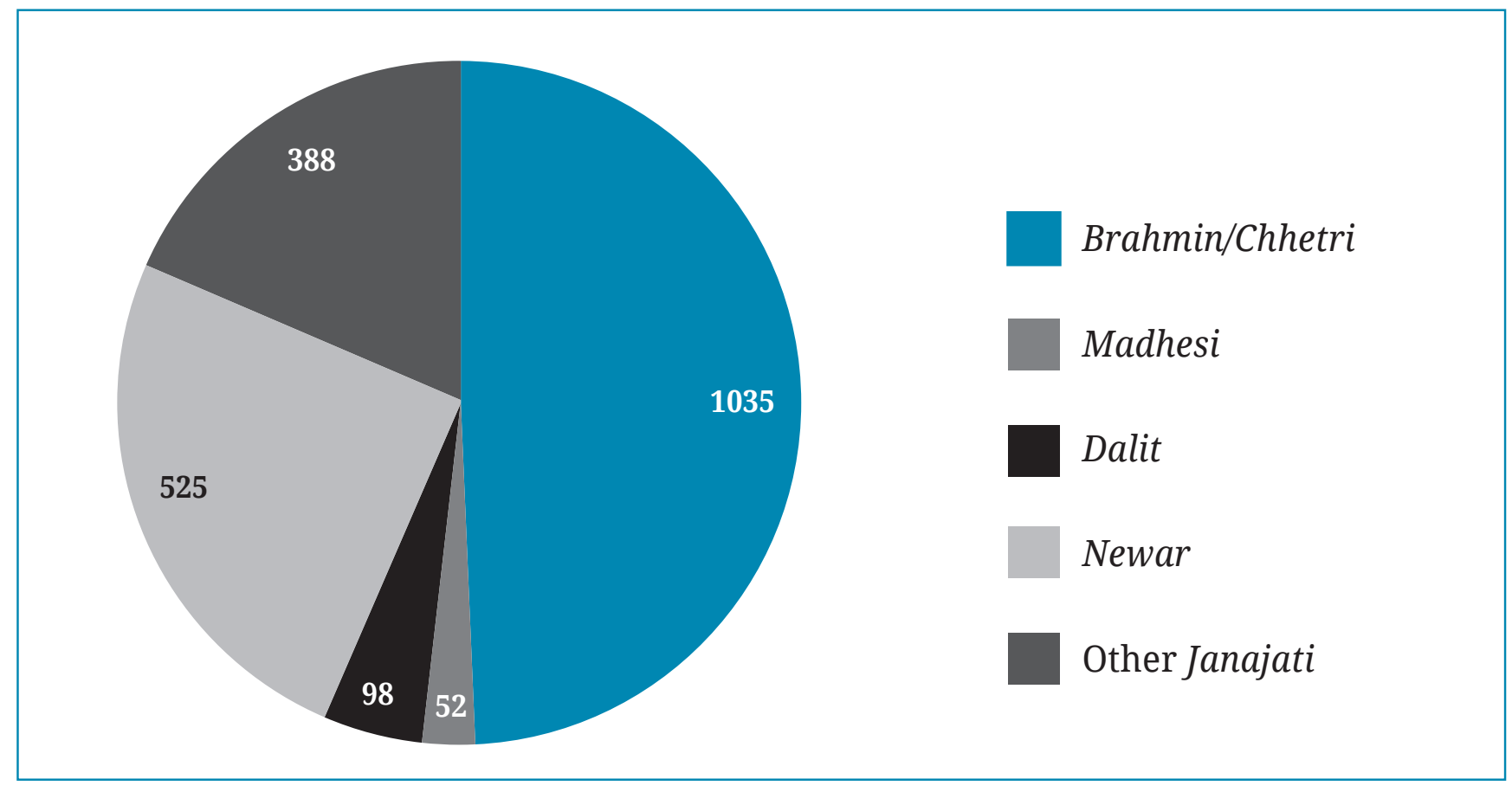

Fig. 1: Caste distribution of the cases 


\section{RESULTS}

Out of the 2098 cases, almost half of the cases were of Brahmin/Chhetri (49.3\%) followed by a quarter of Newar caste $(25 \%)$ and rests were of other castes (Fig. 1). Mean age of the cases was shown in Table-1. There was significant difference in mean age of hysterectomy cases with cervical biopsy cases, $p$ value $<0.0001$ (95\% CI 3.5244 to 5.4156) and that with polypectomy cases, $p$ value $<0.0001$ (95\% CI 1.9884 to 4.8116 ) but there was no significant difference between mean age of cases with cervical biopsy and that of polypectomy, $p$ value $=02332(95 \%$ CI -2.8322 to 0.6922$)$.

\begin{tabular}{|c|c|c|}
\hline Diagnosis & Frequency & Percent \\
\hline Polyp & 312 & 14.9 \\
\hline $\begin{array}{l}\text { Unhealthy cervix or } \\
\text { cervical lesions }\end{array}$ & 429 & 20.4 \\
\hline Premalignant condition & 151 & 7.2 \\
\hline Abnormal uterine bleeding & 364 & 17.3 \\
\hline Prolapse & 279 & 13.3 \\
\hline Fibroid or uterine cause & 411 & 19.6 \\
\hline Ovarian tumours & 113 & 5.4 \\
\hline Other pathology & 39 & 1.9 \\
\hline Total & 2098 & 100.0 \\
\hline
\end{tabular}

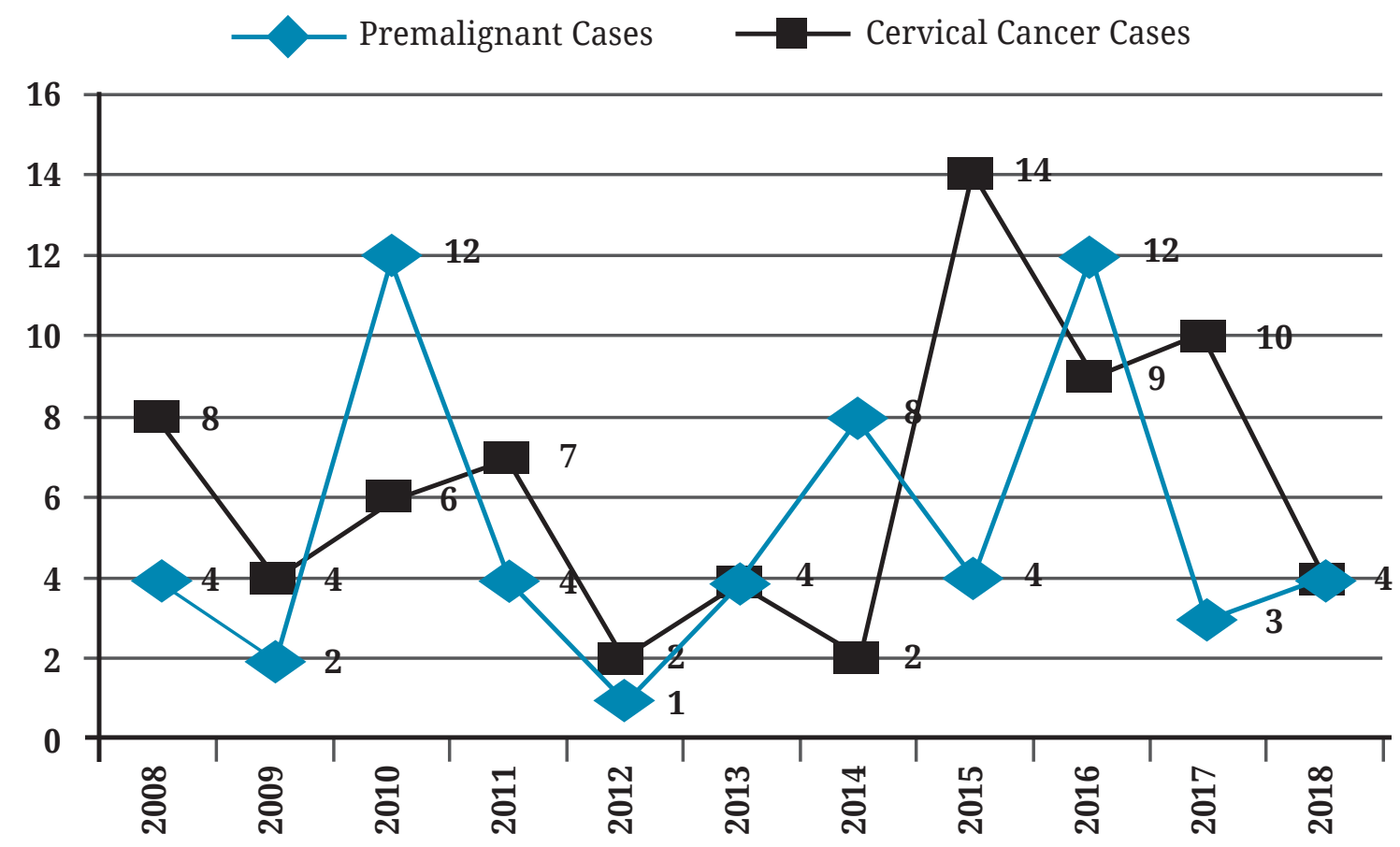

Fig. 2: Year-wise trend of premalignant and cervical cancer cases

Table-1: Distribution of mean age of the cases

\section{Cases}

Overall cases $(\mathrm{n}=2098)$

Cervical biopsy cases

$(\mathrm{n}=721)$

$\begin{array}{cc}\begin{array}{c}\text { Mean age } \\ \text { (years) }\end{array} & \begin{array}{c}\text { Range } \\ \text { (years) }\end{array} \\ 45.68 \pm 10.43 & 20-86 \\ 43,08 \pm 11.50 & 20-86\end{array}$

Cervical polypectomy cases

$(\mathrm{n}=204)$

$33.59 \pm 12.47 \quad 20-81$

Hysterectomy cases

$(\mathrm{n}=1173)$

$47.55 \pm 9.26 \quad 26-79$

The indications for cervical biopsy, polypectomy or hysterectomy were shown in Table-2. Out of 925 cervical specimens (that of biopsy and polypectomy), 168 biopsies were taken under colposcopy guidance. Fifteen premalignant lesions and three cervical cancer cases were detected among 168 biopsies. One hundred seventeen cervical biopsies were taken under hysteroscopy guidance. Out of them, five cases of cervical cancer were detected. Three hundred twenty eight cases had unhealthy cervix and 75 cases had suspicious cervix on clinical evaluation, those cases were scheduled for cervical biopsy. Eighteen premalignant lesions (5.5\%) and three malignant lesions (0.9\%) were detected among 328 unhealthy cervices. Likewise three premalignant lesions (4\%) and twenty three (30.7\%) malignant lesions were detected among 75 suspicious cervices.

Out of 2098 biopsies, $70.2 \%$ were benign lesions, $2.8 \%$ were CIN (cervical intraepithelial neopalsia)/ premalignant lesions, 3.3\% were frank malignant lesions and $23.7 \%$ were normal (Table-3). Likewise, $71.0 \%$ were benign lesions, $5.4 \%$ were 


\begin{tabular}{|c|c|c|c|}
\hline HPE & & $\mathbf{n}$ & $\%$ \\
\hline \multirow{6}{*}{ Benign lesions } & Chronic cervicitis & 728 & 34.7 \\
\hline & Nabothian cyst & 25 & 1.2 \\
\hline & Benign ecto/endocervical polyp & 292 & 13.9 \\
\hline & Squamous metaplasia & 311 & 14.8 \\
\hline & Other benign lesions & 104 & 5.0 \\
\hline & Leiomyoma & 13 & 0.6 \\
\hline \multicolumn{2}{|c|}{ CIN/premalignant } & 58 & 2.8 \\
\hline \multicolumn{2}{|c|}{ Malignancy (cervical) } & 67 & 3.2 \\
\hline \multicolumn{2}{|l|}{ Unremarkable } & 497 & 23.7 \\
\hline \multicolumn{2}{|l|}{ Total } & 2098 & 100.0 \\
\hline
\end{tabular}

Table - 4: Histopathological results among targeted cervical biopsy cases ( $\mathrm{n}=721)$

\begin{tabular}{llcc} 
HPE & & $\mathbf{n}$ & $\mathbf{\%}$ \\
& Chronic cervicitis & 278 & 38.6 \\
& Nabothian cyst & 8 & 1.1 \\
Benign lesions & Benign ecto/endocervical polyp & 121 & 16.8 \\
& Squamous metaplasia & 93 & 12.9 \\
& Other benign lesions & 7 & 0.9 \\
CIN/premalignant & Leiomyoma & 5 & 0.7 \\
Malignancy & & 39 & 5.4 \\
Unremarkable & & 56 & 7.8 \\
Total & & 114 & 15.8 \\
\hline
\end{tabular}

CIN/premalignant lesions, $7.8 \%$ were frank malignant lesions and $15.8 \%$ were normal among targeted cervical biopsy cases $(n=720)$ (Table-4). On caste-wise distribution of premalignant and malignant results among targeted cervical biopsy, Newar and Janajati castes had more premalignant and malignant lesions (Table-5). Year-wise trend of premalignant and cervical cancer cases of $\mathrm{DH}$ was shown in Fig. 2.
We had altogether 110 cases of gynaecological malignancy, cervical cancer was the most common cancer $(67,60.9 \%)$ followed by ovarian cancer $(21,19.09 \%)$ and endometrial cancer $(10,9.09 \%)$. Cervical cancer cases detected in Newar and other Janajati caste were high which is statistically significant ( $p$ value $<0.005$ in both cases) (Table-6). The age group of cervical cancer cases detected among 2098 cases were also analyzed (Table-7).

Table-5: Castewise distribution of premalignant and malignant results among targeted cervical biopsy $(n=721)$

\begin{tabular}{|lccccccc|} 
& Result & $\begin{array}{c}\text { Brahmin/Chhetri } \\
(\mathbf{n}=349)\end{array}$ & $\begin{array}{c}\text { Madhesi } \\
(\mathbf{n}=16)\end{array}$ & $\begin{array}{c}\text { Dalit } \\
(\mathbf{n}=\mathbf{3 7})\end{array}$ & $\begin{array}{c}\text { Newar } \\
(\mathbf{n}=178)\end{array}$ & $\begin{array}{c}\text { Other } \\
\text { Janajati } \\
(\mathbf{n}=141)\end{array}$ & $\begin{array}{c}\text { Total } \\
(\mathbf{n}=721)\end{array}$ \\
$\begin{array}{l}\text { Cervical } \\
\text { biopsy }\end{array}$ & $\begin{array}{c}\text { CIN } \\
\text { Ca }\end{array}$ & $19(5.44 \%)$ & 0 & $2(5.41 \%)$ & $11(6.18 \%)$ & $7(5.97 \%)$ & $39(5.41 \%)$ \\
& Cervix & $25(7.16 \%)$ & $2(12,5 \%)$ & $5(12,51 \%)$ & $6(3.37 \%)$ & $18(12.77 \%)$ & $56(7.77 \%)$ \\
\hline
\end{tabular}

Table-6: Comparison of cervical cancer in Newar and other Janajati castes

\begin{tabular}{|c|c|c|c|c|c|c|c|}
\hline Caste & Cancer & No cancer & $P$ value & Caste & Cancer & No cancer & $P$ value \\
\hline Newar & 6 & 172 & \multirow{3}{*}{0.0116} & Janajati & 18 & 123 & \multirow{3}{*}{0.0134} \\
\hline $\begin{array}{l}\text { Other } \\
\text { castes }\end{array}$ & 50 & 493 & & $\begin{array}{l}\text { Other } \\
\text { castes }\end{array}$ & 38 & 542 & \\
\hline Total & 56 & 665 & & Total & 56 & 665 & \\
\hline
\end{tabular}


Table-7: Age group of cervical cancer cases detected among 2098 cases

\begin{tabular}{|lcc|}
\hline Age group & $\mathbf{n}$ & $\%$ \\
$20-29$ & 1 & 1.5 \\
$30-39$ & 3 & 4.5 \\
$40-49$ & 27 & 40.3 \\
$50-59$ & 17 & 25.4 \\
60 or above & 19 & 28.4 \\
Total & 67 & 100.0 \\
\hline
\end{tabular}

\section{DISCUSSION}

Cervical carcinoma is one of the commonest gynecological carcinoma. ${ }^{1}$ One of the regional studies showed that cervical cancer was seen in $85 \%$ of all gynecologic malignancies in Nepal. ${ }^{11}$ The cancer incidence per 100,000 females was 15.1 in 2003 and 26.7 per 100,000 in 2012. Cancer incidence was low at early age but it was increased with age in both sexes in Nepal. Cervix uteri were the most common site of cancer in females..$^{12}$ The prevalence of cervical cancer was second to breast cancer in females. ${ }^{13}$

Khan et $a l^{13}$ showed that cancer prevalence among the Newars was highest. The majority of local inhabitants in his study site were Newars. Chhetris and Brahmins. Hence the caste-wise cancer prevalence was expected. ${ }^{13}$ The ethnic distribution of the cases of old study was different from our study. The ethnic distribution of State 3 is Tamang $20.42 \%$, Brahmin 18.28\%, Chhetri 17.28\%, Newar $16.92 \%$ and Magar $4.89 \%{ }^{14}$

The mean age of cervical cancer patients was 52.75 years in an earlier study of DH. ${ }^{10}$ This finding was comparable to our study. In a study done by by Bodal et $a l,{ }^{15}$ the mean age of cervical cancer patient was 51.94 years in Indian population.

The cancer incidence in Nepalese female is increased sharply from the age group of 30-34 years. The highest incidence $(140.61$ per 100,000$)$ was found in age group of 65-69 years. ${ }^{16}$ In a study by Jha et al $29 \%$ cases were of cervical carcinoma and about $71 \%$ of them were of age group 40-59 years..$^{17}$ These findings were similar to our study. In our study, cervical cancer was detected in age group of 40-59 years and was significantly high ( $p$ value $<0.005$ ) followed by age group above 60 years.

Crude incidence rates and age standardized incidence rates for cervical cancer increased in China from 2000 to 2014. And, the highest incidence risk was seen in age group of 40-69 years. ${ }^{18}$ The peak age of occurrence of cervical cancer in India is between 55 and 59 years. ${ }^{19}$

The accuracy of colposcopy guided biopsy appears to increase when three biopsy specimens were taken and was particularly high for younger patients. ${ }^{20}$ In this study, only fifteen premalignant cases and three cervical cases were detected out of 168 colposcopy guided procedures. Colposcopy, the single and irreplaceable second-level procedure for triage of cervical abnormalities, is challenged to match the today's screening tests, especially in view of the extended intervals that increase the risks for patients with missed disease. ${ }^{21}$ Bifulco et $a l^{22}$ concluded that the ability of a colposcopist in grading cervical lesion depends on his experience.

Unhealthy cervix with discharge was found to be common even in chronic cervicitis however bleeding and tenderness along with unhealthy cervices were associated with more advanced lesions. ${ }^{6}$ In a study of unhealthy cervices $(n=100)$, $18 \%$ had a positive pap smear. Among 18 positive cases, there were thirteen LSIL and five HSIL but no case of malignancy. On colposcopy, $30 \%$ cases were found to have premalignant lesions. ${ }^{23}$ In a study of 100 pap smear by Pradhan N et al, six had dysplasia in healthy cervix group and eight had dysplasia in unhealthy cervix group. Though, the difference was not statistically significant $(p=0.78)$, dysplasia was slightly higher among the women with unhealthy cervix. ${ }^{24}$ These findings were similar to our study findings. In our study, premalignant lesions (including LSIL and HSIL) were detected in 5.5\% and cervical cancer cases in $0.9 \%$ of 328 unhealthy cervices.

We conclude that cervical biopsy should be performed whenever there is doubt. In cases of unhealthy and suspicious cervices, colposcopy guided cervical biopsy can be the gold standard, and experienced colposcopist should do the procedure. Finally, every hysterectomy specimen must be sent for histopathological evaluation to rule any abnormal lesions in cervix, even if cervical screening was done earlier.

\section{ACKNOWLEDGEMENTS}

I would like to thank all staffs of Department of Obstetrics and Gyanecology and Department of Pathology of DH.

\section{REFERENCES}

1. Ferlay J, Soerjomataram I, Dikshit R et al. Cancer incidence and mortality worldwide: sources, methods and major patterns in GLOBOCAN 2012. Int J Cancer 2015; 136: E359-86. DOI: $10.1002 /$ ijc. 29210

2. Peto J, Gilham C, Fletcher O, Matthews FE. The cervical cancer epidemic that screening has prevented in the UK. Lancet 2004; 364: 249-56.

3. Arbyn M, Sankaranarayanan R, Muwonge R et al. Pooled analysis of the accuracy of five cervical cancer screening tests assessed in eleven studies in Africa and India. Int'l J Cancer 2008; 123: 153-60. DOI 10.1002/ijc.23489 
4. Rathod GB, Singla D. Histopathological vs cytological findings in cervical lesions (Bethesda system) - A comparative study. Int'l Arch Integrated Med 2015; 2: 13-6.

5. Pradhan P. Prevention of carcinoma cervix: role of pap smear screening. Nepal Med Coll J 2003; 5: 82-6.

6. Pradhan B, Pradhan SB, Mital VP. Correlation of pap smear findings with clinical findings and cervical biopsy. Kathmandu Univ Med J 2007; 5: 461-7.

7. Dhaubhadel P, Vaidya A, Choudhary P. Early detection of precursors of cervical cancer with cervical cytology and visual inspection of cervix with acetic acid. J Nepal Med Assoc 2008; 47: 71-6.

8. Marahatta (Khanal) R. Value of conventional cervical cytology as a screening test for cervical cancer. Nepal Med Coll J 2014; 16: 63-7.

9. Tamrakar SR, Chawla CD. A clinical audit of pap smear test for screening of cervical cancer. Nepal J Obstet Gynaecol 2012; 7: 21-4.

10. Dhakal R, Makaju R, Sharma S, Bhandari S, Shrestha S, Bastakoti R. Correlation of cervical pap smear with biopsy in the lesion of cervix. Kathmandu Univ Med J 2016; 55: 254-7.

11. Dhakal HP, Pradhan M. Gynecological malignancy in BPKMCH, Bharatpur. Retrospecive analysis of 321 cases. J Nepal Med Assoc 2001; 40: 108-11.

12. Poudel KK, Huang ZB, Neupane PR. Trends of cancer incidence in Nepal in the period 2003-2012. Asian Pac J Cancer Prev 2016; 17: 2171-5. DOI:http:// dx.doi.org/10.7314/APJCP.2016.17.4.2171

13. Khan GM, Thapa RK, Adhikari DS et al. Cancer prevalence trend in central region of Nepal. $J$ Chitwan Med Coll 2013; 3: 22-5.

14. Status-Paper-Province-3-Nepal [Online]. 2018 Aug 18 [cited 2019 Dec 30];[319 pages]. Available from: URL:https://ocmcm.p3.gov.np/

15. Bodal VK, Brar BK. Correlation of pap smear with histopathological findings in malignant and nonmalignant lesions of cervix. Glob J Med Res E Gynecol Obstet 2014; 14: 19-23.
16. Poudel KK, Huang ZB, Neupane PR. Age specific incidence of five major cancers in Nepal, 2012. Nepal J Epidemiol 2016; 6; 565-73. DOI: 10.3126/nje. v6i2.15163

17. Jha AK, Jha J, Bista R et al. A Scenario of cervical carcinoma in a cancer Hospital. J Nepal Med Assoc 2009; 48: 199-202.

18. Li X, Zheng $\mathrm{R}, \mathrm{Li} \mathrm{X}$ et al. Trends of incidence rate and age at diagnosis for cervical cancer in China from 2000 to 2014. Chin J Cancer Res 2017; 29: 477-86. https://doi.org/10.21147/j.issn.10009604.2017.06.02

19. Sreedevi A, Javed R, Dinesh A. Epidemiology of cervical cancer with special focus on India. Int'l J Women's Health 2015: 7: 405-14. http://dx.doi. org/10.2147/IJWH.S50001

20. Müller K, Soergel P, Hillemanns P, Jentschke M. Accuracy of colposcopically guided diagnostic methods for the detection of cervical intraepithelial neoplasia. Geburtshilfe Frauenheilkd 2016; 76: 182-7. DOI: 10.1055/s-0041-111504

21. Kinney W, Wright TC, Dinkelspiel HE, Defrancesco $\mathrm{M}$, Cox JH, Huh W. Increased cervical cancer risk associated with screening at longer intervals. Obstet Gynecol 2015; 125: 311-5.

22. Bifulco G, De Rosa N, Lavitola G et al. A prospective randomized study on limits of colposcopy and histology: the skill of colposcopist and colposcopy-guided biopsy in diagnosis of cervical intraepithelial lesions. Infect Agents Cancer 2015; 10: 47. DOI 10.1186/s13027-015-0042-9

23. Savitha TS, Waghmare S. A Comparison of pap smear, colposcopy and colposcopy directed biopsy in evaluation of unhealthy cervix. J Evolution Med Dent Sci 2015; 4: 3639-47.

24. Pradhan N, Giri K, Rana A. Cervical cytological study in unhealthy and healthy looking cervix. Nepal J Obst Gynaecol 2007; 2: 42-7. 